\title{
THE FIRST TILTABLE BURNER OF BADISCHE FOR HIGHER ENERGY EFFICIENCY AND LESS REFRACTORY WEAR*
}

\author{
Andreas Volkert ${ }^{1}$ \\ Steven Wohlfarrt ${ }^{2}$ \\ Klaus Libera ${ }^{3}$ \\ Alexander Grosse 4 \\ Andreas Opfermann ${ }^{5}$ \\ Gabriel Stegemann Dieter ${ }^{6}$ \\ Patrick Hansert ${ }^{7}$
}

\begin{abstract}
Energy efficiency, equipment reliability and cost reduction are of the key factors in any efficient plant. Badische Stahlwerke (BSW) started using its own burner technology in 2001, this was developed by Badische Stahl-Engineering (BSE). Over the past 15 years, Badische improved all aspects of its Virtual Lance Burner (VLB), to perfectly fit all steelmaking requirements. This tiltable VLB was first tested at BSW's electric arc furnace no. 2 in 2012. Promising results like reduction of refractory wear, energy efficiency, reliability, etc., were obtained. At the same time the existing VLB system was further improved with regards to the design of the water-cooled copper box. Today in 2016 both EAFs at BSW are equipped with the new patented tiltable system and the new copper box design. The paper will describe the results of the past years at Badische, but will also show the performance at other installations.
\end{abstract}

Keywords: Energy efficiency; Cost reduction; Oxygen injection; chemical energy. 


\section{INTRODUCTION}

Since 1968, Badische Stahlwerke $\mathrm{GmbH}$ (Kehl/Germany) has been operating two electric arc furnaces in Kehl/Germany. Due to continuous training of the people, hardware development and optimization, BSW has become a world-class steel producer operating on a very high level of efficiency. In 2013, BSW produced more than 2.5 million s.t. (2.3 million $\mathrm{mt}$ ) of good billets with two 115 s.t. (104 mt) EAFs. A new goal is to increase production to 3.1 million s.t./year (2.8 million $\mathrm{mt})$ planned in the near future.

Much of the equipment which is operated at the BSW plant has been developed or developed further by Badische Stahl-Engineering $\mathrm{GmbH}$ (Kehl/Germany). By close cooperation with BSW and utilization of the access to BSW's operational facilities, BSE has been able to test its new developments from the beginning under real steel plant conditions and do the required fine-tuning before offering the equipment on the market.

In a think tank, comprising process experts of the steel making plant and design experts of the engineering entity, the team members came to the conclusion that it will be beneficial to combine the strength of a conventional burner with the positive effects of a side wall virtual lance installation. Consequently, the tiltable VLB (T-VLB) has been developed.

This paper shares the experiences of the new system.

\section{DISCUSSION}

History of oxygen technology at Badische Stahlwerke

The Virtual Lance Burner (VLB) Technology at Badische Stahlwerke is part of a holistic oxygen technology application, which consists of oxygen injection by means of a consumable door lance manipulator, oxygen injectors for CO-post combustion and the VLB as a combined tool for burner function during meltdown and oxygen lancing into the steel bath in refining. This concept is a result of a long-lasting development of oxygen technology which has been started with oxygen injection through the slag door with manual lances in 1980. Three years later BSW installed the first burner operated with oil and oxygen in the cold spots of the EAF. In 1985 BSE developed the first Lance Manipulator for oxygen and carbon injection and changed the fuel to natural gas with burners developed in-house. In 1993, BSW installed additional post combustion injectors on a higher level in the EAF in order to pre-heat the scrap in the furnace vessel by using the reaction enthalpy for post combustion.

In 1999 the first multi-functional tools (CoJet $囚$ ) were installed, three in the side wall and one in the EBT panel. Two years later the VLBs were developed with the aim to reach much better equipment availability and to have a tool which can be maintained easily and fast.

Besides oxygen efficiency, availability and maintainability were the main motivation for all further development of the VLB system, which leads to the present 3rd generation of VLB, Figure 1. 


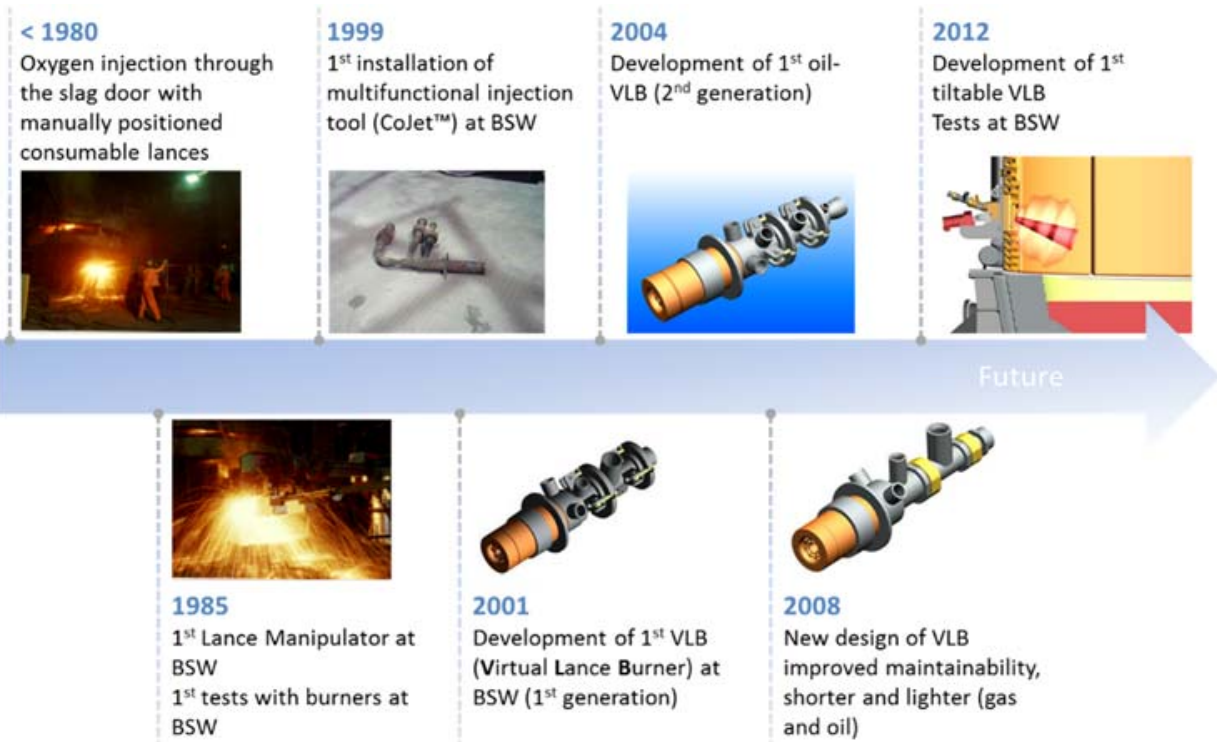

Figure 1: Historical development of oxygen and VLB technology of Badische.

\subsection{Basic ideas for the development of T-VLB}

The demand of reducing the tap-to-tap time at BSW is and has always been a major motivation. Thus oxygen is not only used for metallurgical reasons, but also to substitute electrical energy by chemical energy and to homogenize the thermal profile in the EAF for better melt-down.

The exothermal reactions with oxygen increase the energy density in the EAF and lead to shorter power-on times, which are a function of consumed electrical energy and active power input. The power-on time can be reduced, if the consumed electrical energy consumption can be lowered and the active power input can be increased. Any measures to reach these two objectives are the targets of the continuous EAF optimization process at BSW.

Metallurgical oxygen injection in the steel of the EAF is used to generate all required refining reactions in order to adjust the desired chemical analysis before tapping. In fast EAFs these reactions are often defined by the reaction kinetics. Consequently, the speed of metallurgical reactions can be increased by injecting oxygen not only through the door but also at several other points distributed around the circumference of the EAF. Hence, the multipoint injection of oxygen has to remain.

On the one hand, oxygen injection by VLB can only be successful if the oxygen stream meets the steel surface at a certain angle (around $37.5^{\circ}$ ), which is steeper than the angle of traditional side wall burners (around $20^{\circ}$ ). As the oxygen injection was the main reason for the development of the VLBs the present generation of VLB is mounted at a fixed angle of $37.5^{\circ}$ at BSW. This means that the present VLB is operated at $37.5^{\circ}$ in the lancing mode as well as in the burner mode.

On the other hand, the optimal angle for the burner function is at around $20^{\circ}$. By operating burners at this angle together with tilting the VLB during meltdown of the scrap, the scrap volume pre-heated by the burner flame is bigger. The energy consumed for preheating -if brought by the burner flame - does not need to be brought by electrical energy. Consequently, the idea has been developed to use the VLB in burner mode at angles between $20^{\circ}$ and $35^{\circ}$.

Another issue of using the VLB in burner mode at an angle of $37.5^{\circ}$ is the fact that the burner flame is quite close to the refractory side wall bricks. This leads to a faster refractory wear of side wall bricks below the VLB. If the burner flame can be operated 
at a higher distance from the bricks, a lower refractory consumption is expected and therefore more energy is transferred to the scrap. This does not only result in lower refractory cost, but also - and that is more important for BSW - in an extension of the side wall life time, which increases operating time.

Furthermore, the efficiency of heat transfer from the burner flame to scrap is mainly caused by convection and only to some extent by radiation. The convection heat transfer is expressed by Newton's law:

$\mathrm{Q}=\mathrm{a}^{*} \mathrm{~A}^{*}(\mathrm{~T} 1-\mathrm{T} 2)$

$a=$ heat transfer coefficient, $A=$ surface area (scrap), $T=$ Temperature with $T 1>T 2$

The higher scrap temperature is, or the lower the temperature difference in above equation is, the lower is the heat amount transferred. During the operation of burners the direction of flame remains constant. The burner flames attack the scrap pile from the side wall and heats it up in a certain and limited action zone. In the action zone of the burners the high temperature burner flame heats up the scrap quickly, depending on the size and surface. Finally, the scrap reaches temperatures close to the melting point. In an ideal situation the scrap settles down and leaves the action zone of the flame, which results in lowering the convective contact with the scrap. That means, that heat transfer continues only during a certain period after starting burner operation and then the heat transfer reduces gradually i. The burner efficiency drops down. If the burner flame can penetrate deeper into the EAF both, the pre-heated volume and the burner efficiency increase. Thus the substitution of electrical energy by chemical energy is higher, the electrical energy consumption is reduced and eventually, power-on time is shorter.

Further thinking was directed to the idea, that there is the possibility of changing to higher burner power from presently $199.2 \mathrm{MBTU} / \mathrm{h}$ (3.5 MW) to values of 284.6 MBTU/h (5 MW) and higher.

The idea of the tiltable VLB was born.

\subsection{Technical solution of the tiltable VLB}

The task is to operate the VLB at about $20^{\circ}$ in burner mode for optimal burner function and to inject metallurgical oxygen at $37.5^{\circ}$ in lancing mode with the same tool. To realize a reliable vertical movement was a challenge. But the biggest challenge was to develop a sealing between the movable part and the water cooled box which can resist the demands of a melting process. The sealing has to withstand the difficult environment inside of an EAF, which is defined by high heat, flames, slag and other particles. This sealing has been developed and patented.

After having developed the sealing, the design of the burner unit has been started. The demands of Badische on the engineering were high availability, easy to maintain, compact design at acceptable cost. Furthermore, the cooling water requirement shall not be increased in comparison to the existing VLBs.

A system was developed which can be operated at infinitely adjustable angles between $20^{\circ}$ and $35^{\circ}$ in meltdown as well as between $35^{\circ}$ and $40^{\circ}$ in refining.

Several designs were developed and discussed. Finally Badische decided for the solution of a system consisting of a water-cooled copper frame, a movable water cooled burner casing and a support with integrated hydraulic cylinder. A major challenge was to match the physical dimension of the burner and the hydraulic cylinder. 
For the design of the sealing system it has to be considered, that the gap between the water cooled frame and the burner housing is designed small enough to provide the sealing but also big enough to provide enough cooling.

Included in the system is a software package that adjusts the angle and the flow rates according to the process state of the EAF. The position of the VLB during melting and refining is regulated by the 2-dimensional matrix of $\mathrm{kWh}$ consumed and the TopArc signal, which measures the arc stability in real time.

The movability of the burner has to be guaranteed even if slag splashes occur. For reaching this target, the kinematic of the burner is solved by moving the center of rotation away from the copper frame, Figure 2.
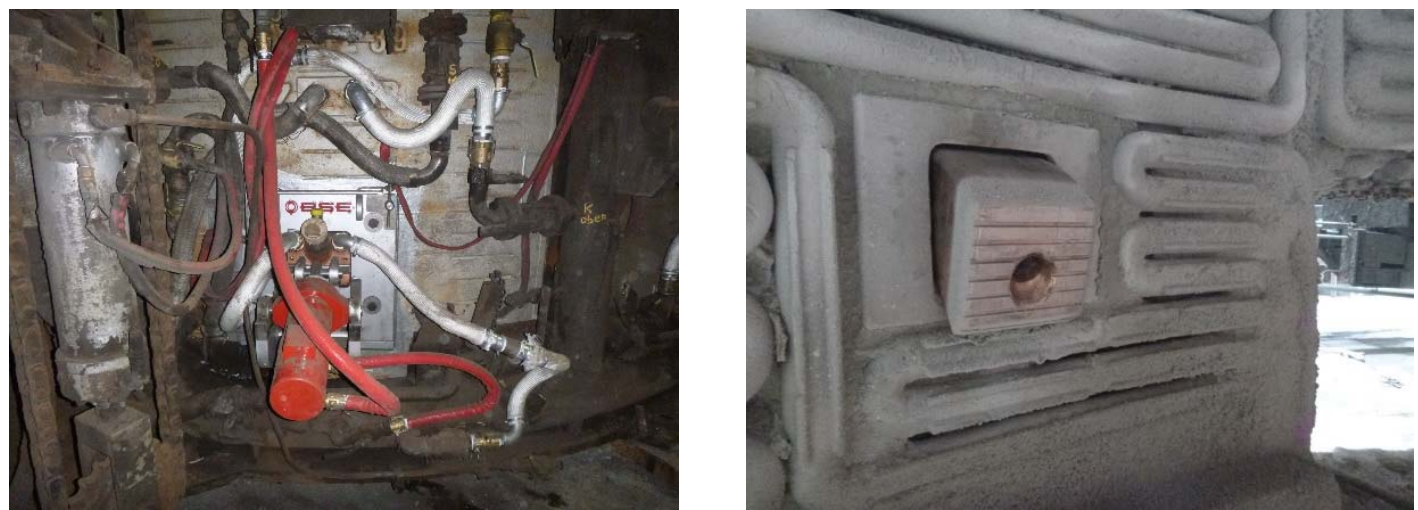

Figure 2: Exterior view of installed tiltable VLB (left) and interior view (right) in a side-wall panel

Thus, the movement of the burner is described by following a curve, so that the burner tip moves inside the furnace at steeper angles (Figure 3). Consequently, slag splashes do not hinder the movability and the penetration point of the lancing stream during refining is further away from the bricks. During lancing the distance between impact point of the oxygen stream and the refractory has been increased by $61 \%$. (Figure 4) ii.
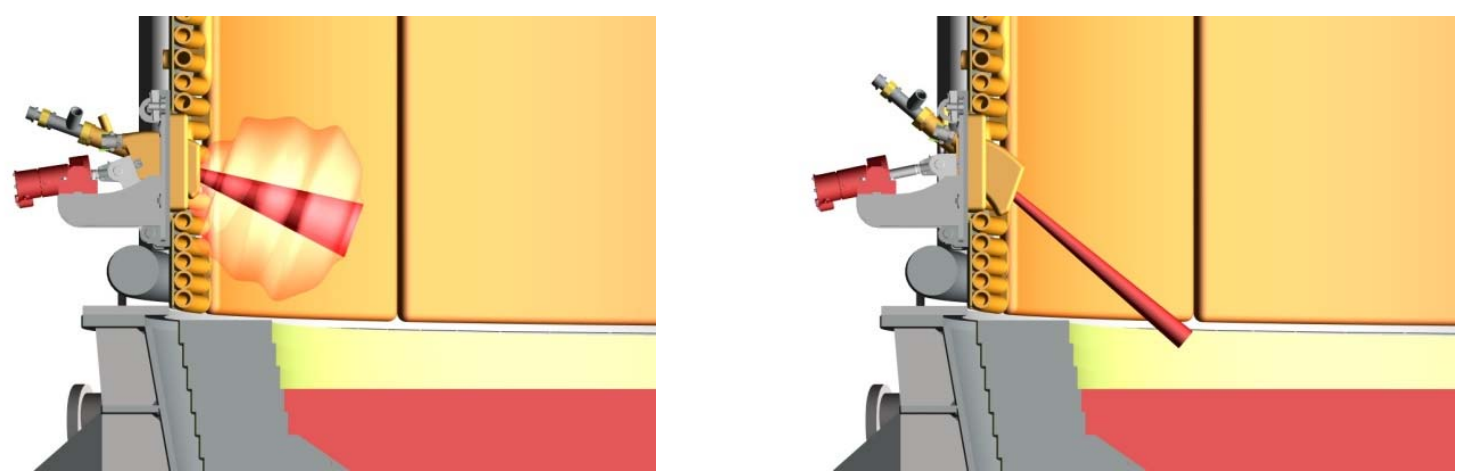

Figure 3: Position of the VLB during melting (left), position of the VLB during lancing (right) 

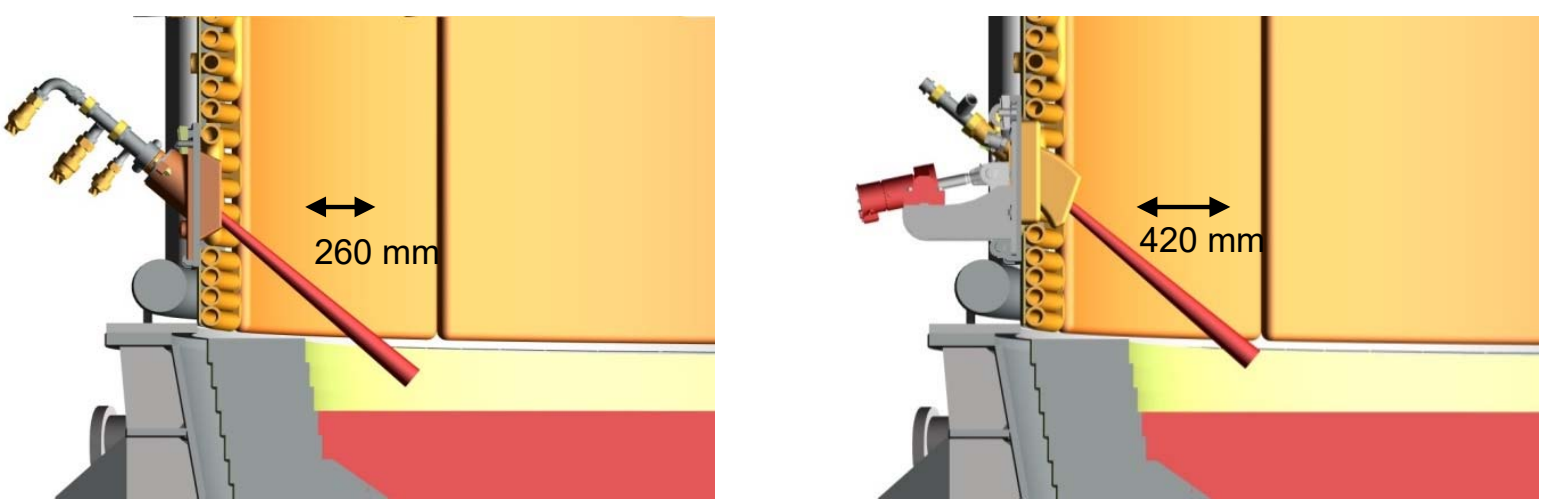

Figure 4: Comparison of distance from refractory bricks (left: old design); (right: new design)

An additional improvement of the VLB design is that the former casing, which was water-cooled, could have been eliminated without any deterioration of the cooling of the pipe in pipe gas and oxygen lances. Now, the cooling of the lances is provided by the cooling of the water-cooled copper box. This has reduced the size, weight and total required water amount of the VLB, Figure 5. Additionally the handling or exchange of lances is even simpler with this new design and can be executed by only one person in less than 15 minutes.

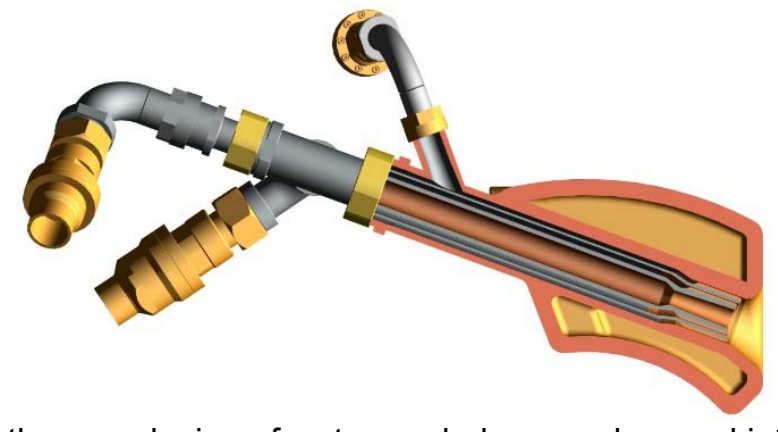

Figure 5: Side view of the new design of water-cooled copper box and integrated lances of VLB

Operational experiences at BSW

The first trials at BSW were started in 2012 at EAF no. 2. In total, 3 testing campaigns were conducted:

1st Campaign November 2012

2nd Campaign March 2013

3rd Campaign October 2013

Figure 6 (left side) shows the VLB in burner mode at an angle of $20^{\circ}$ whereas Figure 6 (right side) indicates the VLB in lancing mode at an angle of $40^{\circ}$.
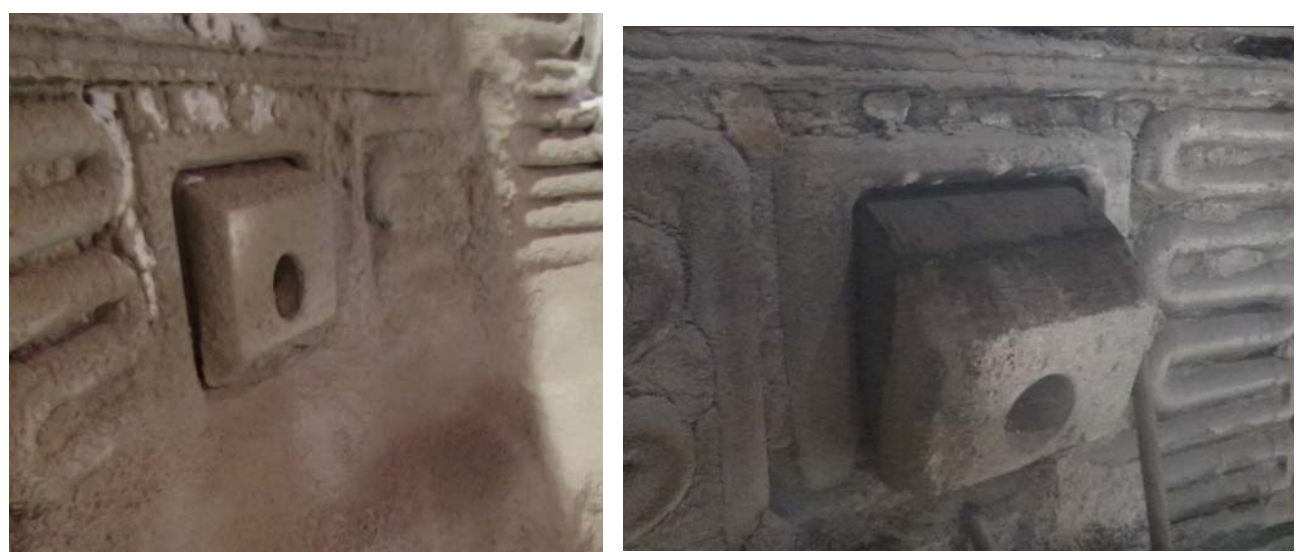

Figure 6: Tiltable VLB in burner position (left) and in lancing position (right) 
Since the last campaign the tiltable VLB has been in operation from October 2013 till today without problems. This has proved the system reliability for more than 10000 heats.Figure 7 shows pictures of the tiltable VLB in operation with different angles for burner mode and lancing mode.
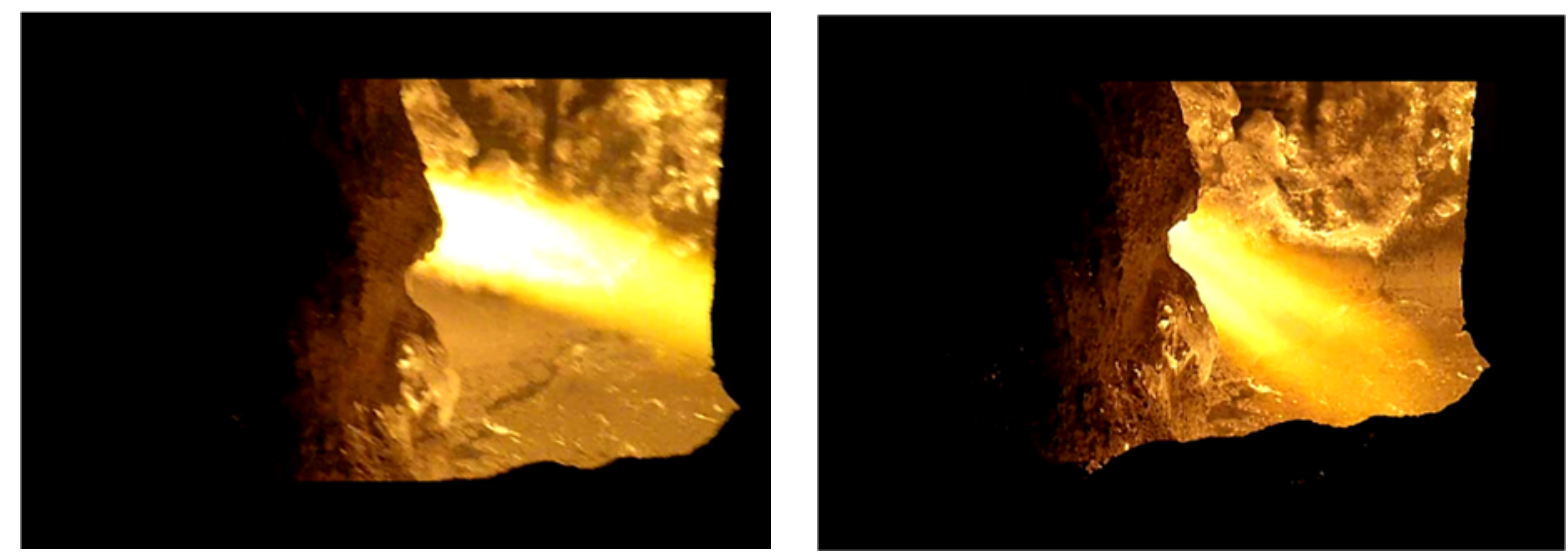

Figure 7: Different operating angles of the tiltable VLB at EAF no. 2 at BSW (left: flat burner mode angle, right: steeper lancing angle)

As the system has proven its reliability under rough steel making environment, BSW decided to install 2 tiltable VLBs at EAF No.1 in February 2015. EAF no. 1 has been constantly revamped in the past in order to cope with a higher tapping weight. That led to the present EAF geometry which is oval. This ovality results in the fact that the distance from the PCD at electrode phase A to the side-wall panel is bigger compared with EAF no. 2 which is nearly round (EAF no.2: $94 \mathrm{inch} / 2407 \mathrm{~mm}$, EAF no. 1: 113 inch/2870 mm). Additionally, the distance from the PCD at Phase $A$ to the side wall panel is $27 \%$ bigger than the distance from the PCD at Phase B to the side-wall panel,

Figure 8. Consequently, the installation of the tiltable VLB were chosen for EAF no. 1, left and right of the slag door, in order to reduce scrap cave ins, un-molten scrap and skulls in these areas.
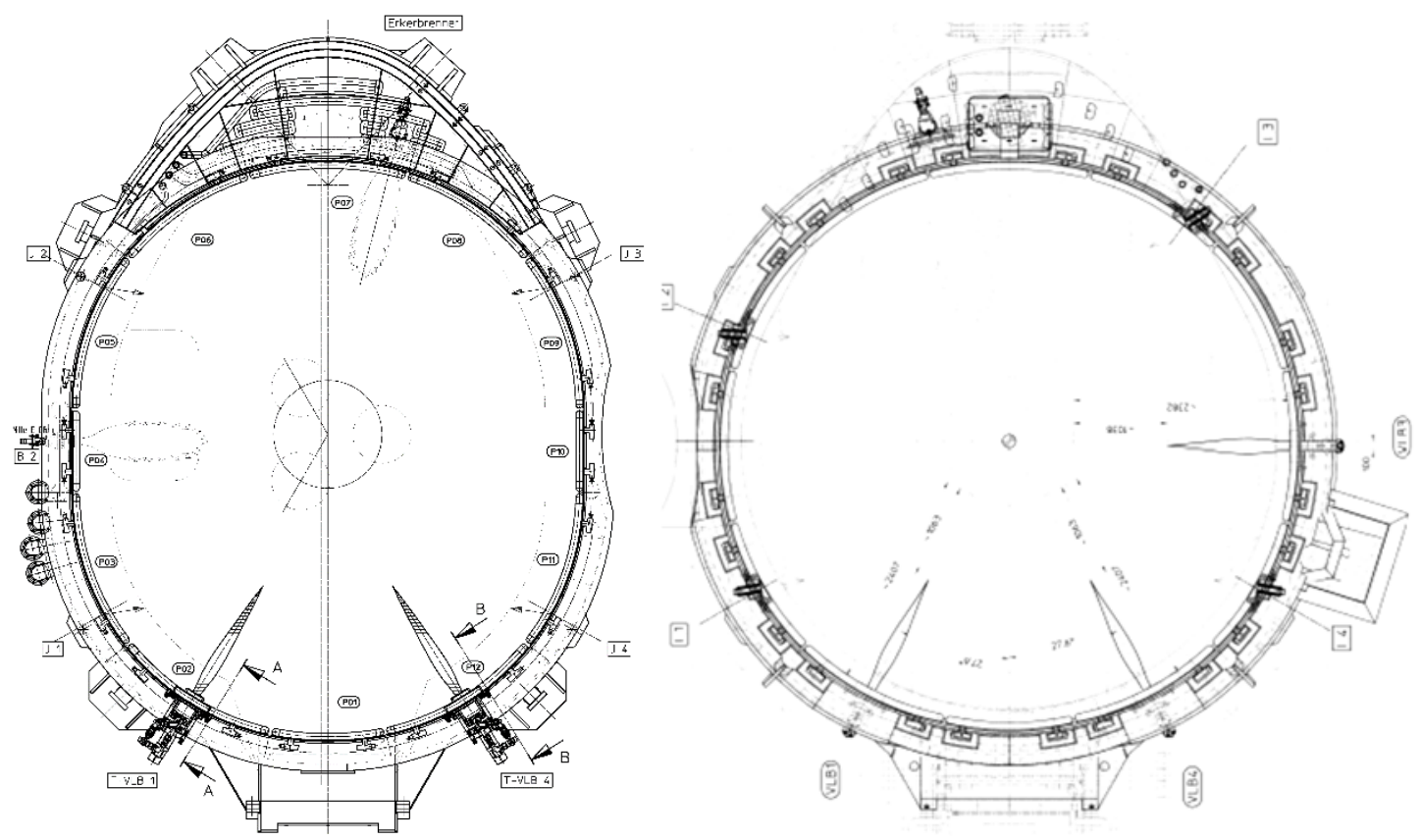

Figure 8: Top View of BSW EAF no. 1with 2 T-VLB (left) and EAF no. 2 (right) 
This measure should lead to less arc extinguishments and arc disturbances, higher active power input by higher arc stability and thus lower power-on times and electrical energy consumptions.

Operational experiences at Stahl Gerlafingen

After having reached the certainty of stable operations at BSW, our sister company Badische Stahl Engineering $\mathrm{GmbH}$ received the order for the installation of tiltable VLBs at Stahl Gerlafingen AG in Switzerland. Stahl Gerlafingen AG belongs to the Italian Beltrame group. The plant produces profiles and reinforcing steels and is the leading Swiss supplier of reinforcing steel products. In 2014 the plant produced approx. 755.000 s.t. (685.000 mt) of good billets iii.

Stahl Gerlafingen operates a Finger Shaft Furnace with a current tapping weight of 83 s.t. (75 mt), followed by LF and 2 CCM machines.

The main targets of Stahl Gerlafingen for the installation of the tiltable VLB is to

Reduce the electrical energy consumption

Reduce the natural gas consumption

Reduce the P-ON time

Increase productivity

Reduce electrode breakages

Reduce refractory consumption

Eliminate/reduce the usage of the water-cooled door lance

Initially, the Finger Shaft Furnace was equipped with 5 oxygen/gas burners with a power of $199.2 \mathrm{MBTU} / \mathrm{h}$ (3.5 MW) each, located at the shaft side, 4 post combustion injectors underneath the shaft, one sidewall, supersonic oxygen injector located on the opposite side of the shaft and one water-cooled door lance for oxygen and carbon injection. Due to severe problems with the supersonic oxygen injector the system was already removed years ago.

The new arrangement with VLB included the replacement of one of the existing burners with a tiltable VLB and to install two additional tiltable VLB at new positions in the side wall, as shown in Figure 9. Furthermore, two post combustion injectors out of four were removed within the new design and two side wall carbon injectors were installed to improve the foaming of the slag. Additionally, BSE supplied the entire automation of the tiltable VLB including PLC and HMI software.

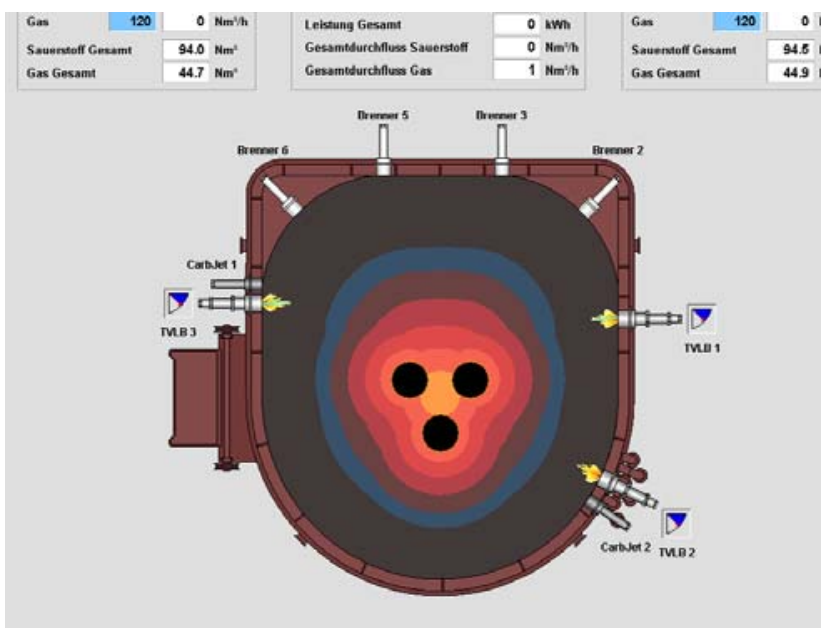

New installation
position of tiltable VLB

Replacement of existing burner by tiltable VLB

New installation position of tiltable VLB

Figure 9: HMI screenshot with positioning of former burner and new tiltable VLB 
The installation of the system started on January 2, 2015 and the first heat was tapped on January 5, 2015 in the morning. Figure 10 shows a top view photo from the shaft furnace with the ignited VLB.

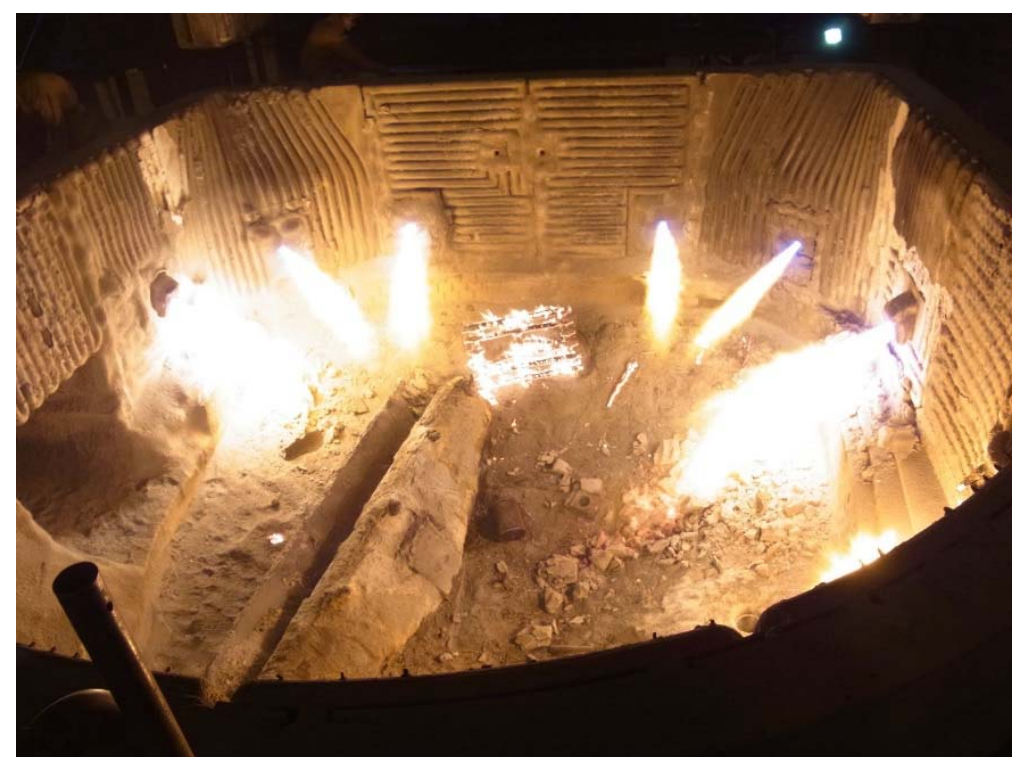

Figure 10: Interior view of the Finger Shaft furnace at Stahl Gerlafingen with installed tiltable VLB

The furnace is operated with a 2 bucket charge, each bucket comprises approx. 45 s.t. $(41 \mathrm{mt})$. The preheated scrap is charged out of the shaft after tapping is completed and the 2nd bucket will be charged immediately while the fingers of the shaft are still open. Then the power is switched on. Once all the preheated scrap has moved through the shaft into the furnace vessel the fingers will be closed and the new scrap bucket is charged into the closed shaft for preheating it for the next heat.

The tiltable VLB no. 1 and 3 (left and right side of the shaft) start with a burner mode as soon as the scrap has moved into the furnace with a flat angle of $21^{\circ}$. During the meltdown of the scrap the burner angle changes to steeper angles (e.g. $25^{\circ}, 30^{\circ}$, etc.) in order to follow the scrap settling in the furnace. Once the refining of the melt starts the VLB are operated with an angle of $40^{\circ}$ and inject oxygen with supersonic speed.

The tilting of the VLB is controlled with an automatic mode based on the parameters arc stability and energy consumption. However, it is also possible to tilt the VLB in manual mode and control the tilting angle from the HMI with preset angles, Figure 11. 


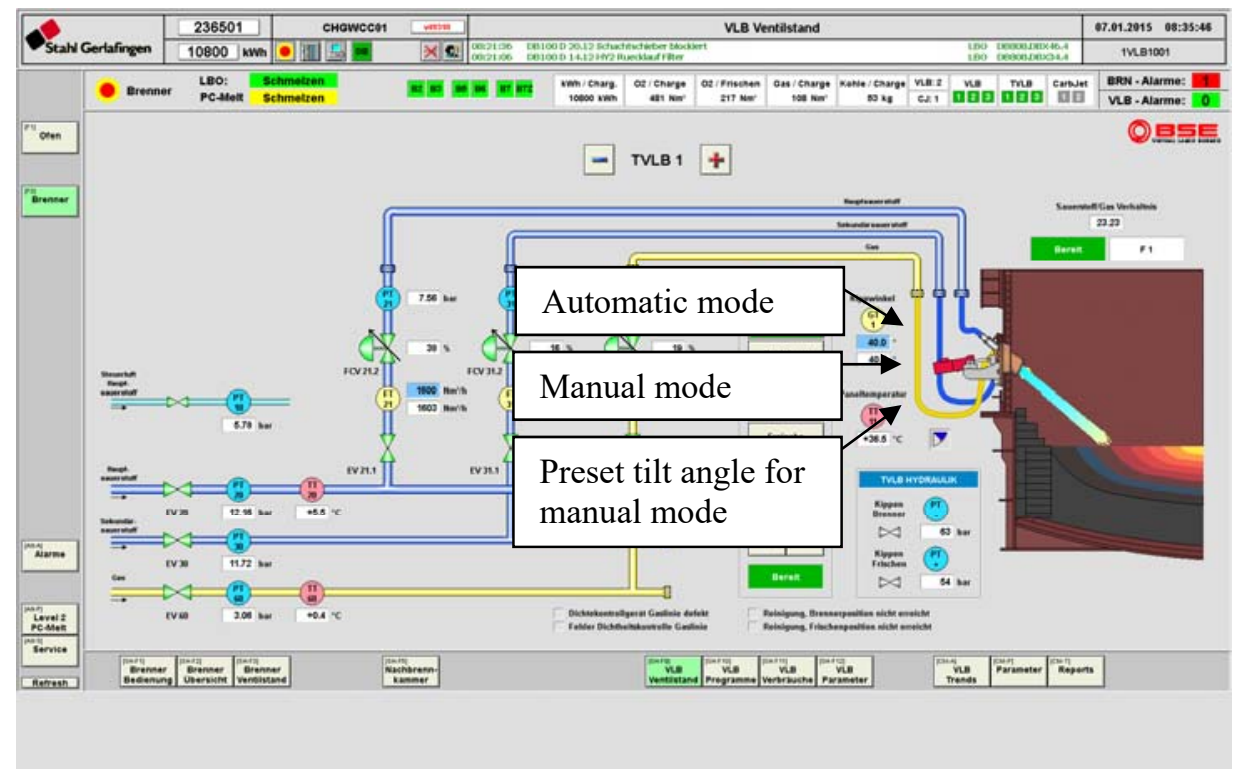

Figure 11: Screenshot of different operating modes of tilting function

After the first heat with the new system was tapped the optimization period began and during the next three days remarkable energy and P-ON time savings were achieved. In

Table 1 and Figure 12 the operational results from before the installation and after are depicted.

Table 1: Heat performance data with reference figures after commissioning the tiltable VLB at Stahl Gerlafingen

\begin{tabular}{|c|c|c|c|c|c|c|c|c|c|c|}
\hline \multicolumn{11}{|c|}{ Performance } \\
\hline $\begin{array}{c}\text { Heat } \\
\text { Number }\end{array}$ & $\begin{array}{l}\text { Power On } \\
\text { Time }\end{array}$ & Power Off & $\begin{array}{c}\text { Energy } \\
\text { Consumption }\end{array}$ & Charge Wt & $\begin{array}{c}\text { Tapped } \\
\text { Steel }\end{array}$ & Yield & Tap Temp. & $\begin{array}{c}\text { Power } \\
\text { input }\end{array}$ & $\begin{array}{c}\text { Oxygen } \\
\text { Consumption }\end{array}$ & $\begin{array}{c}\text { Fuel Gas } \\
\text { Consumption }\end{array}$ \\
\hline & {$[\mathrm{min}]$} & [min] & {$[\mathrm{kWh} / \mathrm{st}]$} & [st] & {$[\mathrm{ts}]$} & $\%$ & {$\left[{ }^{\circ} \mathrm{F}\right]$} & {$[\mathrm{MW}]$} & {$[\mathrm{SCF} / \mathrm{st}]$} & {$[\mathrm{SCF} / \mathrm{st}]$} \\
\hline 1 & 28,2 & 8,5 & 290,9 & 91,2 & 83,9 & $92,0 \%$ & 2967,8 & 51,9 & 1200,5 & 314,3 \\
\hline 2 & 26,7 & 10,2 & 265,1 & 90,2 & 86,7 & $96,2 \%$ & 3009,2 & 51,7 & 1165,2 & 314,3 \\
\hline 3 & 27,8 & 9,2 & 295,0 & 90,1 & 85,8 & \begin{tabular}{|l|}
$95,2 \%$ \\
\end{tabular} & 3014,6 & 54,6 & 1165,2 & 300,1 \\
\hline 4 & 25,8 & 9,1 & 285,6 & 89,1 & 82,6 & \begin{tabular}{|l|}
$92,7 \%$ \\
\end{tabular} & 3059,6 & 54,9 & 1235,9 & 328,4 \\
\hline 5 & 28,4 & 10,1 & 293,5 & 90,8 & 87,6 & $96,4 \%$ & 2969,6 & 54,3 & 988,7 & 201,3 \\
\hline 6 & 26,5 & 8,4 & 289,5 & 91,0 & 83,9 & $92,3 \%$ & 3079,4 & 55,0 & 1235,9 & 317,8 \\
\hline 7 & 26,5 & 23,7 & 285,0 & 91,3 & 84,6 & $92,6 \%$ & 3070,4 & 54,6 & 1271,2 & 367,2 \\
\hline 8 & 25,1 & 10,6 & 281,2 & 90,7 & 83,2 & \begin{tabular}{|l|}
$91,8 \%$ \\
\end{tabular} & 3038,0 & 55,9 & 1200,5 & 310,7 \\
\hline 9 & 28,7 & 14,7 & 293,1 & 90,4 & 88,4 & \begin{tabular}{|l|}
$97,8 \%$ \\
\end{tabular} & 2993,0 & 54,1 & 1165,2 & 271,9 \\
\hline 10 & 27,4 & 8,2 & 295,7 & 90,0 & 83,2 & $92,4 \%$ & 3047,0 & 53,9 & 1129,9 & 264,8 \\
\hline 11 & 27,2 & 9,6 & 301,3 & 89,5 & 83,3 & $93,1 \%$ & 3072,2 & 55,4 & 1129,9 & 257,8 \\
\hline 12 & 25,8 & 13,0 & 268,4 & 91,3 & 85,7 & $93,9 \%$ & 2966,0 & 53,5 & 1306,5 & 353,1 \\
\hline 13 & 27,1 & 10,9 & 278,1 & 89,9 & 84,5 & $94,0 \%$ & 3034,4 & 52,0 & 1306,5 & 356,6 \\
\hline 14 & 29,7 & 25,6 & 281,4 & 90,2 & 83,9 & $92,9 \%$ & 3018,2 & 47,7 & 1412,4 & 434,3 \\
\hline 15 & 25,2 & 12,4 & 265,2 & 90,3 & 84,1 & $93,2 \%$ & 2993,0 & 53,1 & 1306,5 & 353,1 \\
\hline 16 & 28,2 & 9,3 & 301,5 & 90,5 & 79,9 & $88,3 \%$ & 2973,2 & 51,3 & 1412,4 & 377,8 \\
\hline 17 & 25,1 & 25 & 278,2 & 89,3 & 84,1 & $94,2 \%$ & 3014,6 & 55,9 & 1024,0 & 296,6 \\
\hline 18 & 24,4 & 12,6 & 274,5 & 90,4 & 82,3 & $91,1 \%$ & 3011,0 & 55,6 & 1271,2 & 356,6 \\
\hline 19 & 26,4 & 19,1 & 291,8 & 90,3 & 82,3 & \begin{tabular}{|l|}
$91,2 \%$ \\
\end{tabular} & 3030,8 & 54,6 & 1306,5 & 384,9 \\
\hline 20 & 28,9 & 11,9 & 294,5 & 90,1 & 87,2 & $96,8 \%$ & 3011,0 & 53,3 & 1271,2 & 356,6 \\
\hline 21 & 26,2 & 12,6 & 290,9 & 90,0 & 82,2 & $91,3 \%$ & 3016,4 & 54,8 & 1271,2 & 356,6 \\
\hline 22 & 27,4 & 9,4 & 292,7 & 90,2 & 83,7 & $92,8 \%$ & 2971,4 & 53,7 & 1235,9 & 335,4 \\
\hline 23 & 26,2 & 16,5 & 289,1 & 89,7 & 82,5 & $92,0 \%$ & 3036,2 & 54,6 & 1200,5 & 339,0 \\
\hline 24 & 25,8 & 19,1 & 277,3 & 90,6 & 83,1 & $91,7 \%$ & 2973,2 & 53,6 & 1200,5 & 342,5 \\
\hline Average & 26,9 & 13,3 & 285,8 & 90,29 & 84,11 & $93,2 \%$ & 3015,4 & 53,7 & 1226 & 328,8 \\
\hline Reference & 28,3 & & 305,5 & & 74,1 & \begin{tabular}{|l|}
$92,8 \%$ \\
\end{tabular} & 3002 & & 1129,92 & 268,36 \\
\hline Difference & $\mid-1,44$ & & $-19,63$ & & 10,01 & $+0,4 \%$ & & & +96 & +60 \\
\hline
\end{tabular}



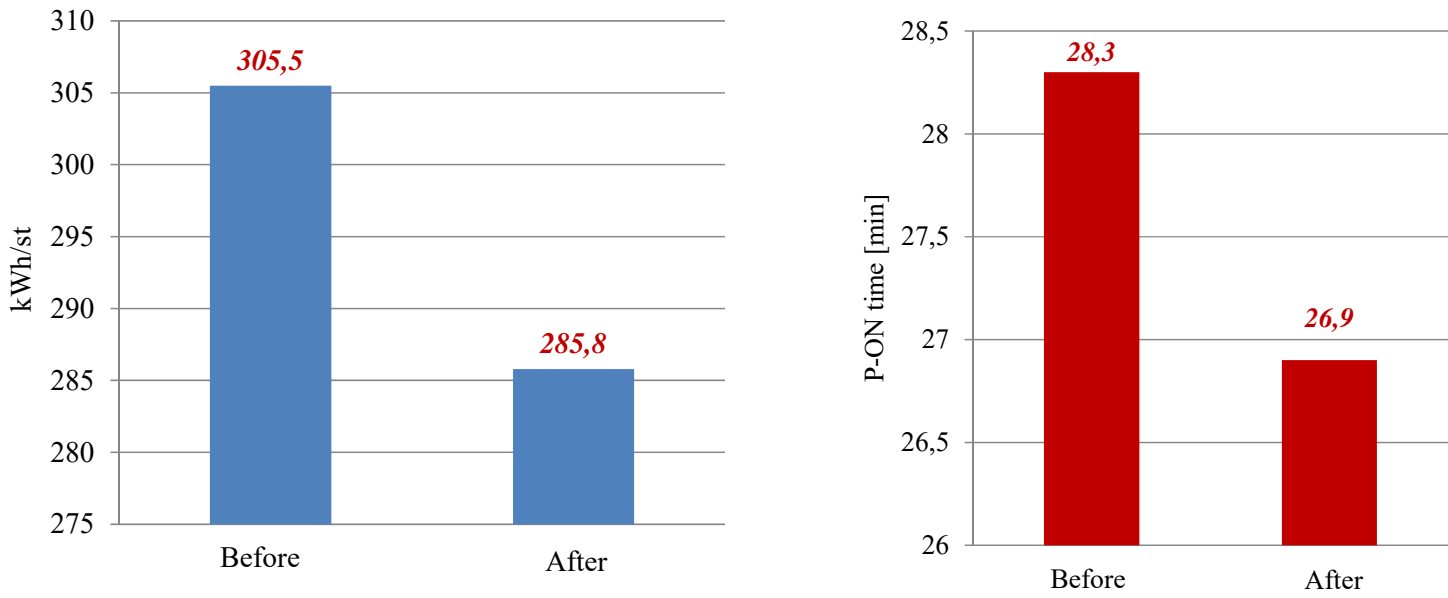

Figure 12: Comparison of performance results from before and after commissioning the tiltable VLB

The savings shown in the diagrams above are in the expected range. However, Stahl Gerlafingen and BSE are cooperating together in order to continuously improve further the achieved results.

Additionally, a trend can be seen up to know that the electrode breakages, resulting from the slipping scrap from the shaft, have been reduced and the overall refractory consumption seems to be lower than before the installation of the tiltable VLB. Particularly the refractory wear in the slag door area seems to be much lower due to reduced usage of the watercooled door lance. These trends have to be further observed for a longer period. The skull formation in the area of the shaft has also been reduced.

\section{CONCLUSION}

BSE developed a tiltable VLB in order to combine the best and most efficient angle for burner mode with the optimum angle for supersonic oxygen injection. Due to the infinite angle adjustments from $20^{\circ}$ to $40^{\circ}$ the scrap heating and melting with burner mode shall be further optimized to reduce the electrical energy consumption. Additionally the refractory wear underneath the burners shall be further mitigated with the new tilting function. Special attention had to be given to the sealing between the tiltable copper box and the holding frame. Therefore BSE developed a new sealing concept for this application which has been patented in 2013. After several functional tests at BSW EAF no.2 the new tiltable VLB has proven its functions and availability in the rough meltshop environment with promising results. In 2014 BSE received the first order for the installation of the tiltable VLB at Stahl Gerlafingen. The commissioning of the system took place in January 2015 and promising results were obtained. Additionally two tiltable VLB were installed at BSW EAF no. 1 in February 2015. The next steps will be now to conduct further optimization tests with the new VLB to utilize the full potential of this unique burner design.

\section{Acknowledgments}

We want to express our gratitude to Stahl Gerlafingen AG for their trust and support during commissioning of the tiltable VLB systems. Furthermore we want to thank all BSW people who supported the tests with the new tiltable VLB and contributed to the results which have been achieved. 


\section{REFERENCES}

1 Y. N. Toulouevski, I. Y. Zinurov: Innovation in Electric Arc Furnaces. Springer-Verlag Berlin Heidelberg 2010, page 118

2 A. Grosse; A. Opfermann; K. Libera, F. Gökce, R. Schweikle, A. Volkert: The next generation of chemical Energy Application of Badische, Proceedings AIST Conference, Indianapolis, USA, 2014

31 http://www.stahlgerlafingen.com/DE/LinkClick.aspx?fileticket=HvW1zBtZS4w\%3D\&tabid=240\&language $=$ de $-\mathrm{CH}$. 